\title{
A review of quality of life themes in Duchenne muscular dystrophy for patients and carers
}

\author{
Lesley Uttley ${ }^{*}$ (D, Jill Carlton, Helen Buckley Woods and John Brazier
}

\begin{abstract}
Duchenne Muscular Dystrophy (DMD) is a severe, life-limiting and incurable condition. However, studies estimating quality of life and those measuring actual quality of life in people living with DMD vary considerably. This discrepancy indicates potential difficulties with assessing quality of life using common generic quality of life instruments in this rare and unique population. This study sought to document the range of themes relevant to quality of life for people with DMD by examining the published literature and additionally to investigate the themes that are relevant to quality of life for carers and the wider family. Eligible studies for the review were primary studies of any study design that reported outcomes or themes relevant to quality of life for either people with $\mathrm{DMD}$, their families, or both. A review of studies identified from searching medical bibliographic sources between 2010 and 2016 found 45 relevant published studies. A thematic framework is proposed to categorise the themes identified into: i. physical; ii. psychological; iii. Social; iv. well-being domains. A final "other" domain was included to encompass themes identified from the literature that are not covered by commonly used quality of life instruments. The rich variety of themes identified from the review highlights that DMD has a complex quality of life profile which is not currently captured by standard quality of life tools that are commonly employed in the healthcare setting. The findings also highlight that the resulting impact on the quality of life of carers and wider family of people with DMD requires consideration.
\end{abstract}

Keywords: Duchenne muscular dystrophy, Literature review, Quality of life, Thematic analysis, Wider family impact

\section{Introduction}

Duchenne muscular dystrophy (DMD) is a rare, inherited neuromuscular disorder affecting boys and men with an estimated incidence of 1:3800 to 1:6200 among boys born alive [1]. The disease is characterised by a progressive degeneration of muscle fibres, which results in muscle weakness. Disruption to daily life can begin as early as aged 3 years, with impact upon daily activities [2]. DMD is incurable and life expectancy is limited, with the average being reported as between approximately 23 and 28 years of age [3]. Gait loss and functional dependence typically occur in the second decade of life [3]. It is recognised that DMD impacts not only the individual, the loss of functional independence is

\footnotetext{
* Correspondence: l.uttley@sheffield.ac.uk

School of Health and Related Research (ScHARR), The University of Sheffield, Regent Court, 30 Regent Street, Sheffield S1 4DA, UK
}

reported to affect quality of life for both children and their families [4-8].

Literature reporting quality of life (QoL) of children with DMD is conflicting. Some studies report reduced QoL $[2,7]$, whilst others find no difference between QoL of children with DMD and healthy children [9-11]. However, it is possible that the findings of such studies were influenced by the way in which QoL was measured within the studies themselves. QoL and health-related QoL (HRQoL) are used interchangeably in the literature, despite being different constructs. QoL is a broad multidimensional concept which is defined by the World Health Organisation as encompassing the person's physical health, psychological state, personal beliefs, social relationships and their relationship to salient features of their environment. Within the context of clinical studies, instruments that actually assess functional ability and/or life satisfaction scales, are often used as a measure of

(c) The Author(s). 2018 Open Access This article is distributed under the terms of the Creative Commons Attribution 4.0 International License (http://creativecommons.org/licenses/by/4.0/), which permits unrestricted use, distribution, and reproduction in any medium, provided you give appropriate credit to the original author(s) and the source, provide a link to the Creative Commons license, and indicate if changes were made. The Creative Commons Public Domain Dedication waiver (http://creativecommons.org/publicdomain/zero/1.0/) applies to the data made available in this article, unless otherwise stated. 
QoL. These instruments frequently study HRQoL which represents the patient's general perception of the effect of illness and treatment on physical, psychological, and social aspects of life. Whilst HRQoL is a multi-domain concept, it may not adequately reflect the full scope of the impact the condition has upon the individual and their overall QoL. A recent study by Wei et al. (2017) [12] found from a study of parents and children with DMD that QoL and HRQoL are related but distinct concepts and that factors outside of 'health' contribute to overall QoL in the paediatric population with DMD. Currently the full range of factors that affect QoL in DMD are unknown.

The perspective from which QoL is measured may also differ. Parent proxy-reports can supplement child self-reports of QoL when a child is too young or unable to complete the assessment. However, there are recognised differences between self and proxy reporting across a range of health conditions relevant to DMD, with parents of children with disabilities tending to report lower HRQoL for their children than the children do for themselves [13-16]. The perspectives of carers for their child and also for their own QoL are therefore also valuable to understanding a more complete picture of the themes underlying QoL.

Currently no condition-specific QoL preference-based measure or conceptual model of QoL in DMD exists for this population. The purpose of this study is to identify what QoL themes are relevant to patients and families of patients with DMD reporting the use of various QoL or HRQoL instruments in this condition in recent published academic literature. "Themes" may be defined as factors that are noted to impact on QoL or noted as being relevant to QoL.

\section{Materials and methods Search strategy}

Searches of MEDLINE (including Medline in Process via OVID), EMBASE (via OVID), and CINAHL (via EBSCO) medical electronic databases were conducted to identify evidence relevant to QoL in people with DMD as well as the effects on family and carers. In order to review the relevant evidence within allocated time constraints, abbreviations to comprehensive review techniques were made including limiting searches to studies published in the English language and those published between 2010 and 2016. In each database, search terms for DMD were combined with four different search statements to identify a variety of research designs. Free text and thesaurus terms were used in combination to maximise sensitivity in the searches using filters. A sample search strategy is provided in Additional file 1.

Titles and abstracts of references retrieved from the searches were assessed for inclusion against a priori established eligibility criteria by one reviewer. Reference lists of included studies were manually searched for further relevant studies that were not captured by the searches. Table 1 outlines the inclusion and exclusion criteria used to screen studies that would be eligible to the review. Studies of interest included primary research studies of people with DMD investigating issues related to the patient, the carer or the family's QoL. This included research designs such as surveys, questionnaires, clinical trials, qualitative research or other designs of QoL research.

\section{Data synthesis}

Studies selected for inclusion were read in full, annotated and coded to extract themes relevant to QoL from the results and discussions sections. One reviewer performed data extraction for QoL themes without blinding to study author. Themes were then pooled across studies into a master database and grouped firstly into domains: i) Physical; ii) Psychological; iii) Social; iv) Well-being as these are commonly encountered domains in general QoL research. Sub-domains within each domain were then created to capture the variety of data from the included studies. Themes that did not fall under any of the four initial domains were grouped under an "Other" domain. This framework of themes was reviewed by one further review author to verify agreement of coding. As the review is not an aggregation of data to provide a

Table 1 Eligibility criteria for studies included in the review

\begin{tabular}{ll}
\hline Inclusion criteria & Exclusion criteria \\
\hline - Patients: Studies of adults and children of any age with a confirmed & - Studies of patients with other forms of MD \\
diagnosis of DMD, and/or of families and carers of people with DMD & - Discussion articles, reviews or editorials without study data \\
- Intervention/Exposure: Measures of quality of life & - Studies published in non-English language \\
- Comparator: Not applicable & - Studies published prior to 2010 \\
- Outcomes: Quality of life & - Observational studies of aetiology or onset \\
- Studies: Studies using QoL instruments or qualitative studies are the & - Studies which are not discussed in relation to QoL \\
primary design of interest. Cross-sectional or cohort studies reporting & - Studies regarding screening for DMD without reference to QoL \\
QoL are eligible. Trials of patients with DMD which report measuring & - Animal studies \\
relevant QoL data in study abstracts will be considered for inclusion. & - Phase 1 clinical studies or lab studies \\
- Studies published after 2010 & - Letters and commentaries \\
& - Citation titles without abstracts \\
\hline
\end{tabular}


pooled treatment effect, or to rank findings based on frequency, no quality assessment or risk of bias assessment was deemed necessary.

\section{Results}

The literature searches yielded 1773 records after duplicates were removed. Figure 1 documents the selection of studies at title and abstract stage. Titles and abstracts were reviewed against eligibility criteria (Table 1) to identify potentially relevant full text articles. A total of 45 studies were identified for inclusion into the review. No further studies were identified from searching reference lists of included studies indicating that the restrictions to English language papers and those published after 2010 are unlikely to have limited the validity of the bibliographic searches.

\section{Included studies}

Table 2 provides the details of the 45 included studies, published from 2010 to 2016. Three studies were conducted in the UK whilst another four were conducted in the UK in combination with other European countries. Nine were conducted in the United States, 16 in European countries and 13 from other countries around the world. The number of participants $(\mathrm{N})$ in the studies ranges from 10 to 770 with a median of 60 . Cross-sectional studies of DMD patients or carers were the most common study design $(n=27)$, followed by case-control $(n=8)$, cohort/ before and after studies $(n=6)$, tool development only $(n=2)$. There was one mixed-methods study (audit, interviews and survey) and one qualitative study. The majority of studies focused on children and adolescents with DMD ( $n=30)$ whilst nine studies were of parents/

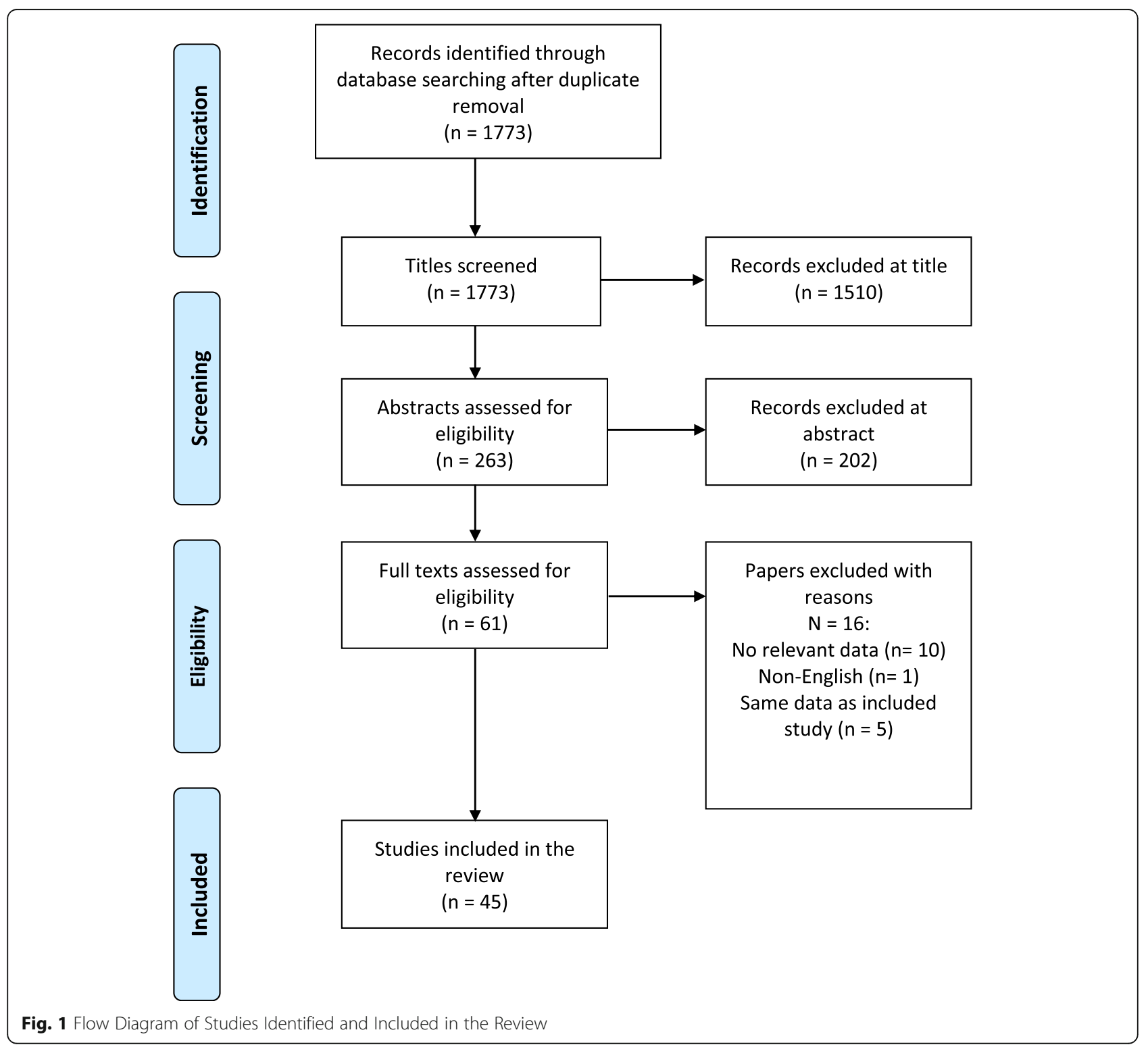


Table 2 Included Studies

\begin{tabular}{|c|c|c|c|c|c|}
\hline First author & Study type & Data source & $\mathrm{N}$ & Country & $\begin{array}{l}\text { Method of quality of life } \\
\text { measurement }\end{array}$ \\
\hline Baiardini et al., 2011 [7] & Cross sectional survey & DMD boys \& families & 27 & Italy & Parent-proxy HRQoL \\
\hline Bendixen et al., 2012 [2] & Case-control survey & DMD boys \& controls & 50 & US & Self-reported QoL \\
\hline Bendixen et al., 2014 [60] & Cross sectional survey & DMD boys by age & 60 & US & $\begin{array}{l}\text { Self-reported participation } \\
\text { in daily activities }\end{array}$ \\
\hline Bloetzer et al., 2012 [61] & Cross sectional survey & DMD boys & 63 & Switzerland & $\begin{array}{l}\text { Parent-proxy sleep } \\
\text { disturbances }\end{array}$ \\
\hline Bray et al., 2011 [62] & $\begin{array}{l}\text { Cohort survey, } \\
6 \text { month follow up }\end{array}$ & DMD boys \& controls & 34 & Australia & Parent-proxy HRQoL \\
\hline Bray et al., 2010 [8] & Cross sectional survey & DMD boys \& parents & 35 & Australia & $\begin{array}{l}\text { Self-reported \& parent-proxy } \\
\text { HRQoL }\end{array}$ \\
\hline Cavazza et al., 2016 [56] & Cross sectional survey & Patients or caregiver & 422 & $\begin{array}{l}\text { UK \& } 7 \text { European } \\
\text { countries }\end{array}$ & $\begin{array}{l}\text { Self-reported or parent-proxy } \\
\text { HRQoL }\end{array}$ \\
\hline Dany et al., 2015 [35] & Tool development & NMD patients & 159 & France & Self-reported HRQoL \\
\hline Davison et al., 2011 [28] & Qualitative study & $\begin{array}{l}\text { DMD \& other NMD } \\
\text { adolescents }\end{array}$ & 13 & UK & $\begin{array}{l}\text { Self-reported social well } \\
\text { being }\end{array}$ \\
\hline Elsenbruch et al., 2013 [20] & Cross sectional survey & $\begin{array}{l}\text { DMD children, } \\
\text { adolescents \& adults }\end{array}$ & 50 & Germany & Self-reported HRQoL \\
\hline Garralda et al., 2013 [30] & Cohort study & DMD boys & 19 & UK & $\begin{array}{l}\text { Emotional impact of } \\
\text { gene-modifying trial }\end{array}$ \\
\hline Geers et al., 2011 [55] & Case-control survey & $\begin{array}{l}\text { DMD children, adults } \\
\& \text { matched controls }\end{array}$ & 36 & Germany & Self-reported HRQoL \\
\hline Heutinck et al., 2015 [27] & Case-control survey & $\begin{array}{l}\text { DMD boys \& healthy } \\
\text { controls }\end{array}$ & 86 & Holland & $\begin{array}{l}\text { Physical activity [respondent } \\
\text { not reported] }\end{array}$ \\
\hline Houwen et al., 2014 [40] & Cross sectional survey & DMD boys \& parents & 40 & Holland & $\begin{array}{l}\text { Self-reported \& parent-proxy } \\
\text { HRQoL }\end{array}$ \\
\hline Hunt et al., 2016 [17] & $\begin{array}{l}\text { Cross sectional interviews } \\
\& \text { survey }\end{array}$ & $\begin{array}{l}\text { DMD boys \& adult } \\
\& \text { parent pairs }\end{array}$ & 12 & UK & $\begin{array}{l}\text { Self-reported \& parent-proxy } \\
\text { QoL }\end{array}$ \\
\hline Klingels et al., 2016 [31] & Tool development & $\begin{array}{l}\text { Systematic review } \\
\& \text { expert opinion }\end{array}$ & 194 & Belgium & Activities of daily living \\
\hline Landfelt et al., 2016 [37] & $\begin{array}{l}\text { Cross sectional } \\
\text { multi-national survey }\end{array}$ & $\begin{array}{l}\text { DMD patients } \\
\& \text { parents \& general } \\
\text { population reference } \\
\text { values from Canada }\end{array}$ & 770 & $\begin{array}{l}\text { UK, Europe } \\
\& \text { USA }\end{array}$ & $\begin{array}{l}\text { Self-reported \& parent-proxy } \\
\text { HRQOL }\end{array}$ \\
\hline Landfelt et al., 2016 [32] & Cross sectional survey & $\begin{array}{l}\text { Caregivers \& general } \\
\text { population reference } \\
\text { values from Canada }\end{array}$ & 770 & $\begin{array}{l}\text { UK, Europe } \\
\& \text { USA }\end{array}$ & Caregiver HRQoL \& burden \\
\hline Lim et al., 2014 [63] & Cross sectional survey & DMD boys \& parents & 63 & US & $\begin{array}{l}\text { Self-reported \& parent-proxy } \\
\text { HRQoL }\end{array}$ \\
\hline Lue et al., 2016 [54] & Cross sectional survey & $\begin{array}{l}\text { DMD adolescents } \\
\& \text { adults }\end{array}$ & 46 & Taiwan & $\begin{array}{l}\text { HRQoL \& global QoL } \\
\text { [respondent not reported] }\end{array}$ \\
\hline Ly et al., 2013 [21] & Cross sectional survey & DMD adults & 10 & US & $\begin{array}{l}\text { Self-reported or proxy social } \\
\& \text { medical support }\end{array}$ \\
\hline Madsen et al., 2014 [22] & Cross sectional survey & DMD adults & 79 & Denmark & Self-reported QoL \\
\hline Magliano et al., 2015 [44] & Cross sectional survey & $\begin{array}{l}\text { Relatives of MD } \\
\text { patients }\end{array}$ & 502 & Italy & Caregiver burden \\
\hline Magliano et al., 2014 [19] & Case-control survey & $\begin{array}{l}\text { DMD parent } \\
\text { vs Becker parent }\end{array}$ & 246 & Italy & $\begin{array}{l}\text { Self-reported caregiver } \\
\text { burden }\end{array}$ \\
\hline Martinsen et al., 2012 [23] & Cross sectional interview & DMD adults & 16 & Denmark & $\begin{array}{l}\text { Self-reported dependence } \\
\text { on care }\end{array}$ \\
\hline Mason et al., 2016 [64] & Cross sectional survey & DMD adults & 29 & Australia & Self-reported QoL \\
\hline McSweeney et al., 2011 [65] & Cross sectional survey & DMD children & 39 & Ireland & $\begin{array}{l}\text { Self- reported \& parent-proxy } \\
\text { HRQoL }\end{array}$ \\
\hline
\end{tabular}


Table 2 Included Studies (Continued)

\begin{tabular}{|c|c|c|c|c|c|}
\hline First author & Study type & Data source & $\mathrm{N}$ & Country & $\begin{array}{l}\text { Method of quality of life } \\
\text { measurement }\end{array}$ \\
\hline Messina et al., 2016 [34] & $\begin{array}{l}\text { Cohort survey, 12-month } \\
\text { follow up }\end{array}$ & Ambulatory DMD & 98 & Italy & $\begin{array}{l}\text { Self-reported \& parent-proxy } \\
\text { HRQOL }\end{array}$ \\
\hline Nozoe et al., 2014 [66] & Cross sectional survey & $\begin{array}{l}\text { Mothers of DMD } \\
\text { children \& control } \\
\text { mothers }\end{array}$ & 20 & Brazil & Parent sexual function \\
\hline Ozyurt et al., 2015 [46] & Case-control study & $\begin{array}{l}\text { DMD, parents } \\
\& \text { controls }\end{array}$ & 17 & Turkey & $\begin{array}{l}\text { Self-reported, parent-proxy } \\
\text { QoL \& parent anxiety }\end{array}$ \\
\hline Pangalila et al., 2015 [42] & Cross sectional survey & DMD adults & 80 & Holland & $\begin{array}{l}\text { Patient HRQoL [respondent } \\
\text { not reported] }\end{array}$ \\
\hline Pangalila et al., 2012 [33] & Cross sectional study & $\begin{array}{l}\text { Parents of severely } \\
\text { disabled DMD adults }\end{array}$ & 80 & Holland & Subjective caregiver burden \\
\hline Peay et al., 2016 [67] & $\begin{array}{l}\text { Cohort survey, } 2 \text { yr. } \\
\text { follow up }\end{array}$ & $\begin{array}{l}\text { Mothers of DMD } \\
\text { children }\end{array}$ & 205 & US & Caregiver burden \\
\hline Peay et al., 2013 [26] & Cross sectional survey & $\begin{array}{l}\text { Parents of DMD } \\
\text { children }\end{array}$ & 119 & US & Caregiver burden \\
\hline Reha et al., 2014 [25] & Cohort survey & DMD patients & 47 & US & $\begin{array}{l}\text { Self-reported or parent-proxy } \\
\text { QoL }\end{array}$ \\
\hline Riss et al., 2012 [68] & Cross sectional survey & DMD boys & 25 & US & $\begin{array}{l}\text { Chart review \& parent-proxy } \\
\text { QoL }\end{array}$ \\
\hline Simon et al., 2011 [11] & Cohort survey, 1 year & DMD patients & 95 & Brazil & $\begin{array}{l}\text { QoL during steroid therapy } \\
\text { [respondent not reported] }\end{array}$ \\
\hline Soares et al., 2015 [45] & Cross sectional survey & $\begin{array}{l}\text { DMD children } \\
\& \text { caregivers }\end{array}$ & 35 & Brazil & $\begin{array}{l}\text { Patient QoL } \\
\text { Caregiver QoL }\end{array}$ \\
\hline Steffensen et al., 2015 [24] & Cross sectional survey & DMD adults & 183 & $\begin{array}{l}\text { UK \& } 6 \text { European } \\
\text { countries }\end{array}$ & Self-reported HRQoL \\
\hline Thomas et al., 2014 [29] & Cross sectional interview & Caregivers & 60 & India & Caregiver burden \\
\hline Uzark et al., 2012 [43] & Case-control survey & $\begin{array}{l}\text { DMD boys, parents } \\
\& \text { matched controls }\end{array}$ & 117 & US & $\begin{array}{l}\text { Self-reported \& parent-proxy } \\
\text { HRQoL }\end{array}$ \\
\hline Wei et al., 2016 [39] & Cross sectional survey & $\begin{array}{l}\text { Families of DMD } \\
\text { boys }\end{array}$ & 176 & Canada & Parent-proxy HRQoL \\
\hline Wei et al., 2014 [41] & Case-control survey & DMD children & 176 & Canada & $\begin{array}{l}\text { Self- report \& parent-proxy } \\
\text { HRQoL }\end{array}$ \\
\hline Wong et al., 2015 [18] & Audit, interviews \& survey & $\begin{array}{l}\text { Clinical records } \\
\& \text { parent survey }\end{array}$ & 49 & Australia & $\begin{array}{l}\text { Parents' experiences from } \\
\text { first noticing symptoms to } \\
\text { receiving a diagnosis }\end{array}$ \\
\hline Zamani et al., 2016 [69] & Case-control survey & $\begin{array}{l}\text { DMD boys, parents } \\
\& \text { healthy controls }\end{array}$ & 85 & Iran & Self-reported \& parent-proxy QoL \\
\hline
\end{tabular}

carers of people with DMD. Six studies were interested in both patient and parent/carer perspectives.

Most studies reported measuring QoL or health-related QoL as the primary outcome of interest. However, some studies were not strictly investigating QoL but did study and report issues that could be of potential relevance to QoL. A variety of named questionnaires and instruments were employed across the studies $(n=36)$ with 18 studies employing multiple instruments. Five studies employed both generic instruments and a specific instrument for paediatric neuromuscular disorders [17-21]. A conditionspecific instrument for QoL in DMD does not currently exist. Table 3 documents the instruments reported across the 45 included studies.
A total of 36 validated instruments were used across the 45 studies. The most commonly employed instruments were the Pediatric Quality of Life Inventory (PedsQL) $(n=9)$, the Short Form-36 (SF-36) $(n=6)$, and the World Health Organization Quality of Life (WHOQoL) $(n=5)$. A small proportion of studies did not provide specific details for the instruments used $(n=7)$ $[18,22-27]$ or they used non-validated questionnaires or interview schedules $(n=8)$ [28-35] or visual analogue scales $(n=2)[20,36]$.

\section{QoL domains identified from the included studies}

Three of the included studies focussed mainly on the development of instruments measuring QoL in the 
Table 3 Survey scales, Questionnaires or Instruments Used across Studies

\begin{tabular}{|c|c|}
\hline Instrument Used & No. of studies \\
\hline $\begin{array}{l}\text { Pediatric Quality of Life Inventory (PedsQL) } \\
\text { neuromuscular module version } 3.0 \\
\text { online }[2,8,17,19,39,41,44,60,61]\end{array}$ & 9 \\
\hline SF-36 Health Survey $[11,28,43,54,55,62]$ & 6 \\
\hline $\begin{array}{l}\text { World Health Organization Quality of Life } \\
\text { (WHOQoL) Scale }[28,43,46,54,62]\end{array}$ & 5 \\
\hline $\begin{array}{l}\text { KIDSCREEN questionnaire (child and adolescent } \\
\text { version and parent version) }[42,63]\end{array}$ & 2 \\
\hline EuroQol (EQ-5D 3 L) [20] (EQ-5D 5 L) [56] & 2 \\
\hline Zarit Caregiver Burden Interview (ZBI) $[20,46]$ & 2 \\
\hline Pittsburgh Sleep Quality questionnaire (PSQI) $[17,64]$ & 2 \\
\hline $\begin{array}{l}\text { Children's Assessment of Participation and Enjoyment } \\
\text { (CAPE) }[2,65]\end{array}$ & 2 \\
\hline $\begin{array}{l}\text { Child Health Questionnaire parent form } \\
\text { (CHQ-PF50) }[7,66]\end{array}$ & 2 \\
\hline Health Utilities Index Questionnaire (HUI) [39] & 1 \\
\hline SF-12 Health Survey [20] & 1 \\
\hline Fatigue Severity Scale [43] & 1 \\
\hline Hospital Anxiety and Depression Scale (HADS) [43] & 1 \\
\hline Barthel Index (BI) [45] & 1 \\
\hline Family Problems Questionnaire (FPQ) [45] & 1 \\
\hline Muscular Dystrophy Care Schedule (MD-CS) [45] & 1 \\
\hline Female Sexual Function Index (FSFI) [64] & 1 \\
\hline Sleep Disturbance Scale for Children (SDSC) [68] & 1 \\
\hline Caregiver Strain Index (CSI) [36] & 1 \\
\hline Self-Rated Burden (SRB) [36] & 1 \\
\hline Care-related Quality of Life instrument (CarerQol) [36] & 1 \\
\hline Family Strain Questionnaire [7] & 1 \\
\hline Family Burden Assessment Scale [33] & 1 \\
\hline COPE Inventory (60-item) [33] & 1 \\
\hline Caregiver Well-Being Scale [33] & 1 \\
\hline $\begin{array}{l}\text { Quality of Life in Neuromuscular Disease } \\
\text { (QoL-NMD) [37] }\end{array}$ & 1 \\
\hline DISABKIDS Questionnaire for 10-16 years [55] & 1 \\
\hline $\begin{array}{l}\text { Depressionsiventar fur Kinder und Jugendliche } \\
\text { (DIKJ) [55] }\end{array}$ & 1 \\
\hline Beck Depression Inventory (BDI) [55] & 1 \\
\hline CARE-NMD questionnaire [62] & 1 \\
\hline State-Trait Anxiety Inventory (STAI) [17] & 1 \\
\hline validated pediatric QOL survey (Still in progress) [67] & 1 \\
\hline Modified Brooks Scale (MBS) [67] & 1 \\
\hline Life Satisfaction Index for Adolescents (LSI-A) [11] & 1 \\
\hline Quality of Life Evaluation Scale (AUQUEI) [11] & 1 \\
\hline Activity Limitations (ACTIVLIM) [65] & 1 \\
\hline
\end{tabular}

patient population [21, 35, 37]. The remaining 42 studies covered a large variety of topics relevant to people with DMD and their carers'. Themes from all 45 studies were extracted and coded into the following five domains: i) Physical; ii) Psychological; iii) Social; iv) Well-being and; v) Other. The first four domains were derived from an initial a priori framework to encompass the commonly anticipated domains in general QoL research. Based on the number, variety and recurrence of themes identified across the included literature, the domains were further divided into relevant sub-domains as presented in Table 4. An "other" domain was created to capture themes recurring and potentially relevant that may be regarded independently to the four initial domains. Themes were assimilated across studies into one framework to encompass and summarise the diversity of research.

The domains and sub-domains were derived from either studies measuring self-reported QoL of people with DMD, parent proxy estimations, parent/carer/ family specific or general public estimations. Themes are presented by domain and sub-domain for people with DMD in Tables 5 and carers of people with DMD in Table 6.

Table 4 Quality of Life Domains and Sub-Domains Identified Across the Included Studies

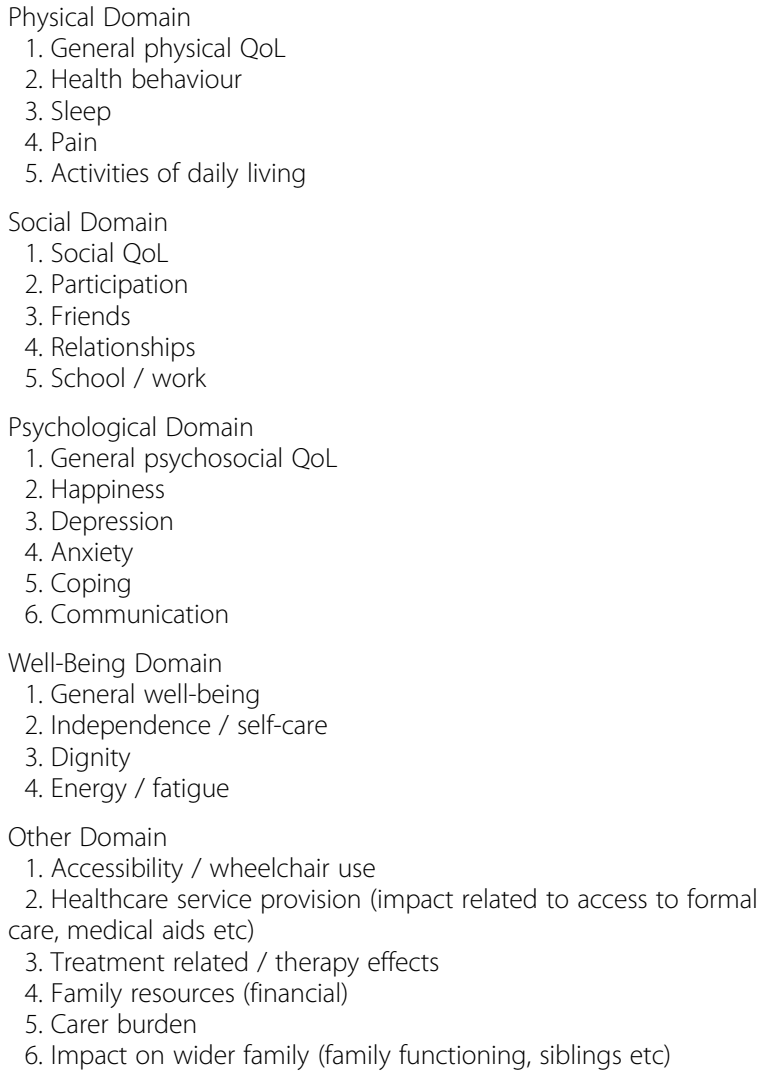


Table 5 Themes and Trends Identified Under the Physical, Psychological, Social, Well-being and Other Domains for DMD Patients

\begin{tabular}{|c|c|}
\hline \multicolumn{2}{|c|}{ Physical Functioning Themes } \\
\hline \multirow[t]{11}{*}{$\begin{array}{l}\text { General physical } \\
\text { QoL }\end{array}$} & $\begin{array}{l}\text { Impaired QoL according to decline in } \\
\text { ambulatory status [54] }\end{array}$ \\
\hline & $\begin{array}{l}\text { Impaired QoL reported (according to both } \\
\text { self-report [44], and parent-proxy report }[44,60]\end{array}$ \\
\hline & Self-report higher than parent [8] \\
\hline & Declines with age $[19,22,61]$ \\
\hline & $\begin{array}{l}\text { Impaired compared to controls/normative } \\
\text { data }[24,42,55,62]\end{array}$ \\
\hline & Varies according to geographical status [28] \\
\hline & Impairment correlates with anxiety [43] \\
\hline & $\begin{array}{l}\text { Impairment correlates with wheelchair or } \\
\text { ventilator use }[7,19]\end{array}$ \\
\hline & $\begin{array}{l}\text { Physical functioning QoL improvement with } \\
\text { treatment [29] }\end{array}$ \\
\hline & $\begin{array}{l}\text { Fractures occur more frequently in more } \\
\text { ambulant stages [63] }\end{array}$ \\
\hline & $\begin{array}{l}\text { Physical activity lower than for age-matched } \\
\text { controls }[2,31,60]\end{array}$ \\
\hline \multirow[t]{4}{*}{ Health Behaviour } & $\begin{array}{l}\text { Physical activity less strenuous than } \\
\text { age-matched controls [31] }\end{array}$ \\
\hline & $\begin{array}{l}\text { Physical activity decline with age by } \\
\text { self-report [64] }\end{array}$ \\
\hline & $\begin{array}{l}\text { More on-screen/sedentary behaviour with } \\
\text { age [31] }\end{array}$ \\
\hline & $\begin{array}{l}\text { Physical activity improvement with treatment } \\
\text { by self-report or parent proxy [29] }\end{array}$ \\
\hline \multirow[t]{2}{*}{ Sleep } & $\begin{array}{l}\text { Sleep quality lower than controls by self-report } \\
\text { or parent proxy [17] }\end{array}$ \\
\hline & $\begin{array}{l}\text { Problems initiating and maintaining sleep (DIMS), } \\
\text { sleep-related breathing disorders and sleep } \\
\text { hyperhidrosis by parent-proxy [65] }\end{array}$ \\
\hline \multirow[t]{4}{*}{ Pain } & Pain correlates with reduced QoL [22] \\
\hline & $\begin{array}{l}\text { Occurrence of pain not reflected in associations } \\
\text { of general QoL [43] }\end{array}$ \\
\hline & $\begin{array}{l}\text { Pain complaints largely kept within the } \\
\text { family [22] }\end{array}$ \\
\hline & $\begin{array}{l}\text { Physical abilities restrict pain-coping } \\
\text { strategies [22] }\end{array}$ \\
\hline \multirow[t]{2}{*}{$\begin{array}{l}\text { Activities of Daily } \\
\text { Living }\end{array}$} & $\begin{array}{l}\text { Problems with day-to-day practicalities } \\
\text { compounds problems in other domains [32] }\end{array}$ \\
\hline & $\begin{array}{l}\text { Daily activities such as transportation to school } \\
\text { are passive for majority of patients whereas } \\
\text { controls use active transport [31] }\end{array}$ \\
\hline \multicolumn{2}{|l|}{ Social Themes } \\
\hline General Social QoL & $\begin{array}{l}\text { Lower QoL for social domain than unaffected } \\
\text { boys }[2,19,24,32,55,61,62]\end{array}$ \\
\hline \multirow[t]{3}{*}{ Participation } & $\begin{array}{l}\text { Adolescents expressed longing for missed } \\
\text { activities }[44,54]\end{array}$ \\
\hline & $\begin{array}{l}\text { Children perceive their ability to keep up with } \\
\text { their peers as less difficult than their parents } \\
\text { do [67] }\end{array}$ \\
\hline & $\begin{array}{l}\text { Inability to participate in activities with peers } \\
\text { further aggravates social problems }[24,44,54]\end{array}$ \\
\hline
\end{tabular}

Table 5 Themes and Trends Identified Under the Physical, Psychological, Social, Well-being and Other Domains for DMD Patients (Continued)

\begin{tabular}{|c|c|}
\hline & $\begin{array}{l}\text { Lack of correlation between decrease in } \\
\text { participation and general QoL [2] }\end{array}$ \\
\hline & $\begin{array}{l}\text { Low level of participation leads to life devoid } \\
\text { of meaningful activities [43] }\end{array}$ \\
\hline & $\begin{array}{l}\text { Social activities and participation not correlated } \\
\text { with "social relationships" [37] }\end{array}$ \\
\hline & $\begin{array}{l}\text { Decline of social participation with increasing } \\
\text { age }[2,64]\end{array}$ \\
\hline & $\begin{array}{l}\text { Significantly more time spent on screen time } \\
\text { activities that controls [31] }\end{array}$ \\
\hline & $\begin{array}{l}\text { Decrease in participation correlates with time } \\
\text { to walk up stairs and decrease in physical } \\
\text { activities [64] }\end{array}$ \\
\hline \multirow[t]{5}{*}{ Friends } & $\begin{array}{l}\text { Adolescents expressed longing for missed } \\
\text { friends }[32,54]\end{array}$ \\
\hline & $\begin{array}{l}\text { Children and parents rate their children as } \\
\text { having lower QoL regarding "friends" than } \\
\text { controls }[44,60]\end{array}$ \\
\hline & $\begin{array}{l}\text { Parents perceive lower HRQoL for social } \\
\text { acceptance than their sons self-report [42] }\end{array}$ \\
\hline & $\begin{array}{l}\text { Accessibility to homes becomes a physical } \\
\text { barrier to visiting friends [27] }\end{array}$ \\
\hline & $\begin{array}{l}\text { Carers have crucial role in enabling patients } \\
\text { to see family and friends [27] }\end{array}$ \\
\hline \multirow[t]{2}{*}{ Relationships } & $\begin{array}{l}\text { Score low in the domain of social relationships } \\
\text { compared to reference population }[32,43]\end{array}$ \\
\hline & $\begin{array}{l}\text { Few patients had expectations of successful } \\
\text { future relationships [32] }\end{array}$ \\
\hline \multirow[t]{5}{*}{ School/Work } & $\begin{array}{l}\text { Most common school problem was missing } \\
\text { school to go to doctor or hospital [44] }\end{array}$ \\
\hline & $\begin{array}{l}\text { Parent report more school days missed because } \\
\text { of not feeling well than their children [67] }\end{array}$ \\
\hline & $\begin{array}{l}\text { No difference to controls for "school-related" } \\
\text { QoL [2] }\end{array}$ \\
\hline & $\begin{array}{l}\text { Parents report practical difficulties with sending } \\
\text { their child to school [33] }\end{array}$ \\
\hline & $\begin{array}{l}\text { Hopes for future employment and education } \\
\text { attenuated by lack of independence and } \\
\text { difficulties accessing work experience [32] }\end{array}$ \\
\hline \multicolumn{2}{|c|}{ Psychological Themes } \\
\hline \multirow[t]{5}{*}{ Psychosocial QoL } & $\begin{array}{l}\text { Psychosocial QoL lower than general paediatric } \\
\text { public([7], \#1851, }[19,44])\end{array}$ \\
\hline & $\begin{array}{l}\text { Older patients did not tend to perceive lower } \\
\text { psychosocial QoL despite increased physical } \\
\text { limitations }[44,55]\end{array}$ \\
\hline & $\begin{array}{l}\text { Patients receiving corticosteroids report no } \\
\text { difference in psychosocial QoL compared } \\
\text { with patients not receiving steroids [44] }\end{array}$ \\
\hline & $\begin{array}{l}\text { Mental health QoL varies according to } \\
\text { geographical status (better in North Western } \\
\text { than Eastern Europe) [28] }\end{array}$ \\
\hline & $\begin{array}{l}\text { Family income associates with better Generic } \\
\text { Core Psychosocial score [19] }\end{array}$ \\
\hline \multirow[t]{2}{*}{ Happiness } & $\begin{array}{l}\text { Most patients rated as happy and in good health } \\
\text { by caregivers compared to public preference } \\
\text { which estimates substantial impairment [39] }\end{array}$ \\
\hline & Parents rated their children lower for "general \\
\hline
\end{tabular}


Table 5 Themes and Trends Identified Under the Physical, Psychological, Social, Well-being and Other Domains for DMD Patients (Continued)

\begin{tabular}{ll}
\hline & mood" and feelings than control parents [42, 60] \\
& Parents rated their children lower for "moods \\
and emotions" than their children's \\
self-report [42] \\
Depressive symptoms were in the subclinical \\
range and did not correlate with physical \\
disability [24] \\
Correlated with overall QoL and with physical \\
health and psychological functioning [43] \\
Patients worried about their future and about \\
their family [44] \\
Emotional impact of trial participation mediated \\
by baseline psychosocial stressors [34] \\
Communication with family and friends is an \\
important coping mechanism [44] \\
Coping mechanisms posited as reason for \\
maintenance of psychosocial QoL in older \\
boys [55] \\
Communication difficulties mean patients not \\
always able to provide self-assessments [39, 66] \\
Parents underestimate their child's HRQoL \\
compared to self-report [67] \\
Motor impairments mean dependence on \\
help to complete assessments may introduce \\
reporting bias [19, 24, 44] \\
Dependence on help to complete assessments \\
may inhibit respondents from admitting extent \\
of feelings [24, 44] \\
Patients often found it difficult to talk to \\
non-medical people [44] \\
Patients rely on familiar people to be able \\
to communicate effectively [22, 27, 44] \\
Well-Being Themes \\
Perceived Hnication \\
Com
\end{tabular}

General Well-Being Perceived HRQoL underestimated by parents compared to self-perception by self-report [42]

Independence/ Parents help required to complete Self-Care self-assessment [39]

Patients become increasingly dependent on parent/carer with age $[26,27,37]$

Patients dependent on parents and carers to act on their behalf to relieve pain [22]

When patients are less able to take care of themselves independently, they perceive their physical abilities lower [42]

Parents help required to complete self-assessment [39]

Patients become increasingly dependent on parent/carer with age $[26,27,37]$

Dignity Many patients consider their QoL as good and feel respected by society [26]

Creative engagement and hobbies important to feelings of identity and autonomy [27]

Attitudes to accessibility are of great importance to patient's integration in society [19]

Importance of patient's needs and wishes as an individual to be respected [27]
Table 5 Themes and Trends Identified Under the Physical, Psychological, Social, Well-being and Other Domains for DMD Patients (Continued)

\begin{tabular}{ll}
\hline Energy/Fatigue & Less fatigue correlates with better QoL $[19,41]$ \\
& Low QoL for fatigue reported by patients $[42,43]$ \\
& Lower QoL for fatigue reported by patients than by \\
& patients [67]
\end{tabular}

Other Themes

Accessibility/ Use of electric wheelchairs can promote participation in Wheelchair Use activities [54]

Affordable access to medical devices is central to maintenance of QoL as physical functioning deteriorates [39]

Access to public transport and access to the professional world were barriers to participation [32, 37]

Intermittent wheelchair use associated with greater fatigue than children not using a wheelchair [19]

Wheelchair use correlates with poorer QoL $[7,19]$

Lack of wheelchair access to premises can be a barrier to participation and social activities [27]

Healthcare Service Earlier diagnosis benefits include ability to access Provision specific treatments sooner, preparing for financial and practical issues in the future and informing reproductive planning [23]

Large proportion of carers report adequate professional support [45]

Medical (e.g. splints, shower chairs) and leisure equipment (PlayStation) can exacerbate or influence pain [22]

Choices of equipment, seating, beds and routes of medication should be available to carers [22]

Patients felt nurses were sometimes not adequately trained in ventilator care [25]

Lack of knowledge from primary healthcare providers on the specific complications of DMD [25]

All adult patients ( $>20 \mathrm{yrs}$.) required help around the clock [26]

Main driver of non-healthcare costs to the healthcare system is informal care [56]

Treatment Related/ Some medications were difficult for patients to swallow Therapy Effects

whilst others had side effects [22]

Providing pre-emptive analgesics and adjunctive medication for common side effects alongside should be considered [22]

Potential emotional impact of trial participation on patient and family [34]

Higher incidence of fracture for patients on steroids [63]

\section{Important and recurring trends in the data}

Particular trends in the data were noted during the course of the review. The tendency for the general public to estimate the HRQoL of people with DMD lower than the patients themselves, or the so-called disability paradox [38], was observed indicating the potential for preference-based measures that necessarily incorporate public views to underestimate QoL in DMD. Two studies documented substantial differences between public 
Table 6 Themes and Trends Identified Under the Physical, Psychological, Social, Well-being and Other Domains for Carers Carer: Physical Functioning Themes

General Physical Correlates with burden $[8,18,45,60]$

QoL

Sleep Poor quality of sleep correlates with hormonal changes related to stress [61]

Poor quality of sleep correlates with sexual dysfunction [61]

Carer: Psychological Themes

Happiness Indicate similar levels of happiness to the general population [36]

Depression PARENT: Correlated with annual household cost burden and hours of leisure time devoted to informal care per week [20]

High number of relatives report feelings of depression [45]

Patient's loss of ambulation reported as most emotionally difficult time for parents [62]

Parents report feelings of loss about child's condition $[18,45]$

Anxiety

Correlated with annual household cost burden and hours of leisure time devoted to informal care per week [20]

No difference between anxiety levels of patient mother versus controls [17]

High number of relatives report feeling worry about future of other family members [45]

Higher anxiety correlated with less active coping style [36]

Parents prioritised the worries about affected children and their care before worries regarding themselves [30]

Coping Psychological adaptation to DMD predicted by resilience [63]

Parents felt unable to bear the situation longer compared to parents of Becker MD [18]

Active coping style correlates with lower caregiver burden [36]

Emotional coping was most disrupted around the time of loss of ambulation [62]

Coping strategies such as positive reinterpretation and religion correlate with understanding of the illness [33]

Social support an important coping strategy [33]

Communication Difficulties communicating about the condition with affected sons [33]

Carer: Social Themes

Participation Constraints in leisure activities and neglect of hobbies frequently mentioned concern from parents [18]

Perception of stigma in a public setting [18]

Friends

Psychological burden higher in those with lower social contacts and support from friends/relatives in emergencies [18]

Relationships Psychological burden higher for parents without a cohabiting partner [45]
Table 6 Themes and Trends Identified Under the Physical, Psychological, Social, Well-being and Other Domains for Carers (Continued)

Parents report interpersonal issues or problems in family functioning [33]

Carer: Well-Being Themes

General Well- Caregiving described not only as a burden but Being as an important, rewarding activity [18, 33, 36]

Caregiver well-being rated as moderate [33]

Carer: Other Themes

Accessibility/

WheelcHair use

Patient's transition to wheelchair reported as most emotionally difficult time [62]

Treatment Related/

Parental concern about getting right treatment

Family resources Family income restricts abilities to care for son $[20,30,33,45]$

Higher family income correlates with better HRQoL $[19,20,36]$

Carer Burden Higher perceived caregiver burden correlated with worse functional status in the child $[18,44,45,63]$

Higher psychological burden in those who did not live with a partner $[45,64]$

Practical burden correlates with daily time in taking care of the patient $[33,45]$

Higher burden in relatives of DMD patients compared with LGMD and BMD [45]

High number of relatives report feeling guilt for having transmitted the illness to their children [45]

Burden correlates with duration of illness $[18,62,65]$

Burden higher among those with fewer social contacts and lower social support in emergencies $[18,33]$

Parent concerns about quality of care their sons received and problems with physical distance if/ when their sons leaves home [36]

Relates to time caring for children not functional dependence [46]

Carer age has no correlations with other factors relevant to burden [62]

Impact on Wider Family

DMD parents are significantly different to Becker MD parents for feelings of stigma and neglect of hobbies [18]

Parents believed MD has a negative influence on the psychological well-being, and social life of unaffected children [18]

Difficulties among healthy siblings reported as higher by parents who were older, had higher burden and lower social contacts [18]

Support from own social contacts relied upon in event of carer illness [45]

Substantial differences between $\mathrm{DMD}$ and BMD caregivers ability for night waking; neglect of hobbies; work/household difficulties; taking holidays and financial difficulties [18]

Substantial number of parents believed patient's condition negatively influenced psychological 
Table 6 Themes and Trends Identified Under the Physical, Psychological, Social, Well-being and Other Domains for Carers (Continued)

well-being of unaffected children [18]

Fathers reported lower levels of satisfaction with the family relationship than mothers [7]

Some parents reported interpersonal issues of problems in family functioning [33]

Substance use reported to be higher among male caregivers [33]

Carer: Physical Functioning Themes

$\begin{array}{ll}\text { General Physical } & \text { Correlates with burden }[19,44,62,70] \\ \text { QoL } & \text { Poor quality of sleep correlates with hormonal } \\ \text { Sleep } & \text { Phanges related to stress [66] } \\ & \text { Poor quality of sleep correlates with sexual } \\ & \text { dysfunction [66] }\end{array}$

Carer: Psychological Themes

Happiness Indicate similar levels of happiness to the general population [33]

Depression PARENT: Correlated with annual household cost burden and hours of leisure time devoted to informal care per week [32]

High number of relatives report feelings of depression [44]

Patient's loss of ambulation reported as most emotionally difficult time for parents [62]

Parents report feelings of loss about child's condition $[19,44]$

Anxiety

Correlated with annual household cost burden and hours of leisure time devoted to informal care per week [32]

No difference between anxiety levels of patient mother versus controls [46]

High number of relatives report feeling worry about future of other family members [44]

Higher anxiety correlated with less active coping style [33]

Parents prioritised the worries about affected children and their care before worries regarding themselves [26]

Coping Psychological adaptation to DMD predicted by resilience [67]

Parents felt unable to bear the situation longer compared to parents of Becker MD [19]

Active coping style correlates with lower caregiver burden [33]

Emotional coping was most disrupted around the time of loss of ambulation [62]

Coping strategies such as positive reinterpretation and religion correlate with understanding of the illness [29]

Social support an important coping strategy [29]

Communication Difficulties communicating about the condition with affected sons [29]
Table 6 Themes and Trends Identified Under the Physical, Psychological, Social, Well-being and Other Domains for Carers (Continued)

\begin{tabular}{ll}
\hline Participation & $\begin{array}{l}\text { Constraints in leisure activities and neglect of } \\
\text { hobbies frequently mentioned concern from } \\
\text { parents [19] }\end{array}$ \\
& Perception of stigma in a public setting [19] \\
Friends & $\begin{array}{l}\text { Psychological burden higher in those with lower } \\
\text { social contacts and support from friends/relatives } \\
\text { in emergencies [19] }\end{array}$ \\
Relationships & $\begin{array}{l}\text { Psychological burden higher for parents without } \\
\text { a cohabiting partner [44] } \\
\end{array}$ \\
& Parents report interpersonal issues or problems \\
in family functioning [29]
\end{tabular}

Carer: Well-Being Themes

General Caregiving described not only as a burden but

Well-Being as an important, rewarding activity $[19,29,33]$

Caregiver well-being rated as moderate [29]

Carer: Other Themes

Accessibility/ Patient's transition to wheelchair reported as most Wheelchair Use emotionally difficult time [62]

Treatment Parental concern about getting right treatment Related/ for child and missing out on new treatments [26]

Family Resources Family income restricts abilities to care for son $[26,29,32,44]$

Higher family income correlates with better HRQoL $[32,33,41]$

Carer Burden Higher perceived caregiver burden correlated with worse functional status in the child $[19,43,44,67]$

Higher psychological burden in those who did not live with a partner $[44,61]$

Practical burden correlates with daily time in taking care of the patient $[29,44]$

Higher burden in relatives of DMD patients compared with LGMD and BMD [44]

High number of relatives report feeling guilt for having transmitted the illness to their children [44]

Burden correlates with duration of illness [19, 62, 65]

Burden higher among those with fewer social contacts and lower social support in emergencies $[19,29]$

Parent concerns about quality of care their sons received and problems with physical distance if/ when their sons leaves home [33]

Relates to time caring for children not functional dependence [45]

Carer age has no correlations with other factors relevant to burden [62]

Impact on Wider DMD parents are significantly different to Becker Family $\quad$ MD parents for feelings of stigma and neglect of hobbies [19]

Parents believed MD has a negative influence on the psychological well-being, and social life of unaffected children [19]

Difficulties among healthy siblings reported as 
Table 6 Themes and Trends Identified Under the Physical, Psychological, Social, Well-being and Other Domains for Carers (Continued)

higher by parents who were older, had higher burden and lower social contacts [19]

Support from own social contacts relied upon in event of carer illness [44]

Substantial differences between DMD and BMD caregivers ability for night waking; neglect of hobbies; work/household difficulties; taking holidays and financial difficulties [19]

Substantial number of parents believed patient's condition negatively influenced psychological well-being of unaffected children [19]

Fathers reported lower levels of satisfaction with the family relationship than mothers [7]

Some parents reported interpersonal issues of problems in family functioning [29]

Substance use reported to be higher among male caregivers [29]

preference estimates for QoL in DMD compared to patients [20,39]. These variations are in line with previous literature $[38,40]$ on the topic of incorporating different perspectives in health state valuation and highlight the need to fully consider the reasons behind these differences and the potential consequences of low agreement.

Agreement between patients and their carers tended to be consistent across domains. However, as noted by other research [13-16] a number of studies found that patients with DMD rate their QoL more favourably by self-report compared to their caregivers' proxy report $[19,39,41,42]$. A variety of reasons for this are posited across these studies. Parents own fears and worries about their child's disease may influence their assessment of their child's HRQoL [19]. Children may have adapted to their illness better than their parents have and parents may not always have the most accurate assessment of their child's internal state [19]. Also, parents may reflect on their own frame of reference by interpreting the limitations of their sons or they may be more sensitive to negative comments of the environment [42]. Reasons postulated for low agreement between self- and proxy report appear most relevant to differential processes of adaptation between children and their parents.

Alternatively, if the notion that parents underestimate their child's QoL is rejected, it is conceivable that children may have overestimated their QoL under certain circumstances. For example, one study suggested that when tests were completed with help of the paediatricians who are conducting the assessment, an element of reporting bias may be introduced [24]. Patients were noted as less likely to mention pain as one of their complaints [43]. The issue of pain, and the communication of pain, is a potentially relevant factor to the issue of differences between self and proxy reports of QoL. One study [22] reports that patients were limited in their ability to manage their own pain and may only confide in pain to parents even though these discussions might need prompting. In this respect children are dependent on their parents or carers correctly picking up on their behavioural and emotional indicators of pain. The reluctance of the young men to talk about their pain may be linked to this reliance on other people to take action on their behalf [22]. Therefore, those interested in measuring HRQoL should be aware of potential response biases that may mean that relevant factors to patients' well-being are overlooked. The consequences of parental underestimation of their sons' QoL could have a negative effect on decision making when boys are too ill to speak for themselves [8]. One study found that boys reported more worry than appreciated by parents which in turn may interfere with communication and the parent's understanding of their child's psychosocial needs [44]. Here the importance of communication is evident as well as the accuracy of parent-proxy estimations in the absence of the child being able to complete a self-report.

\section{Interventions called for in the literature}

There were a number of suggestions for interventions required for people with DMD and their families discussed in the included studies. Whilst not directly relevant to QoL they may provide further information about which QoL domains were regarded as important to patients and their families. These included, but are not limited to: initiatives to relieve family burden and improve carer well-being [18, 20,33, 45, 46]; social skills training and modified activities inclusive of children with limited mobility [41]; education and care focused on optimising participation [43]; strategies to avoid diagnostic delay [23]; routine screening questionnaires and vigilance for signalling symptoms of pain, depression and anxiety in patients [43]; and improvements to welfare policies to simplify bureaucratic procedures [45].

\section{Further research called for in the literature}

Suggestions for future primary studies included research investigating the effect on other family members $[17,18$, 45]; studies with follow up, rather than cross-sectional designs [17-19, 44]; studies with more diverse samples with regards to race, educational status and single-parent families [44]; and further validation of the QoL-NMD [37].

\section{Discussion}

This study has highlighted a large variety of quantitative research and few qualitative studies investigating QoL in DMD patients and carers. A large number of themes and trends in the data were identified by the authors of the included studies as being relevant to the QoL of 
people with DMD, their carers' and their families. The physical, psychological, social and well-being domains and each of their subdomains are populated by several themes, many of which are commonly already known about DMD. Some themes were identified however, which are not commonly investigated using validated instruments, particularly those under the "other" domain. These themes highlight the complexity and uniqueness of the DMD as they relate to the importance of accessibility, communication, particularly regarding proxy versus self-report, the relationship to and impact upon the carer, and also the importance of appropriate healthcare services or family resources. These themes are unlikely to be adequately assessed for DMD patients by generic preference-based QoL instruments.

\section{Understanding the range of impact to QoL from DMD}

This review included studies that used either quantitative and/or qualitative methods to determine the impact of DMD on QoL. However, there were very few qualitative studies identified, with most studies using an instrument to measure the impact of DMD on QoL. The included studies employed a wide range of different instruments that are relevant to QoL. This is common in the investigation of QoL, particularly for children [47]. Given complexities specific to DMD, the difficulties of using a generic HRQoL instrument in a specific disease area were acknowledged. Baiardini et al (2011) [7] suggested it would be impossible to use the same measure of HRQoL for all DMD patients due to the age range of affected patients. Another study which employed the QoL-NMD, an instrument specific to neuromuscular disease, even reported that that were some categories that were covered by a more generic scale (the INQoL) that were not covered by the more disease-specific QoL-NMD [37]. These authors recommended that a questionnaire specific to each neuromuscular disorder should be developed on the basis that whilst genetic neuromuscular disorders share a common pattern (i.e. a progressive loss of physical condition), they are also heterogeneous on several criteria. These include the age of disease onset, muscles affected, and the range of severity between the beginning and the end of the disease. Therefore, DMD can be considered as quite unique within the broader category of neuromuscular dystrophy.

\section{Relevance and validity of instruments used in the studies} A key benefit of using generic HRQoL instruments is the comparability of findings across clinical areas, for example, to estimate cost-effectiveness of interventions. Commonly employed generic HRQoL instruments such as the SF-36 and WHOQoL-BREF were used with different levels of success in the included studies. Landfeldt et al (2016) found that the SF-12 indicated that DMD patients had normal physical health where the EQ-5D did not [20]. Pangalila et al (2015) found that the occurrence of pain, anxiety and depression were not reflected in the QoL results using the WHO-QoL BREF and that only the 'social relationships' domain of QoL was impaired compared to the reference population [43]. Houwen-van Opstal et al (2014) highlights that the PedsQL, which is the most frequently used instrument in this review, was not designed to assess the full range of functioning unlike KIDSCREEN-52 [42]. The relationship between QoL and physical functioning is noted to be a complex, non-linear one with QoL for both children and/or carers potentially improving following the loss of ambulation where the risk of children falling is removed and the use of adaptive medical aids becomes routine. The same authors also highlight that there is no specific outcome measure to assess participation levels in patients. This issue was seen to be particularly lacking for people with DMD and their families. They also note that the use of generic HRQoL instruments sometimes means the inclusion of some inappropriate questions, such as "were you able to run well?" for patients with DMD.

The included literature identified varied aspects of physical, psychological and social implications of DMD. As stated, these were primarily measured using quantitative methods via existing QoL instruments. Table 3 shows that the common instruments used were PedsQL (neuromuscular module), SF-36, and WHOQOL. However, it can be argued that the SF-36 and WHOQOL instruments are not necessarily appropriate for the DMD population, as being that these instruments are generic, they do not incorporate all factors that are relevant to QoL for people with DMD. The PedsQL Neuromuscular Module (PedsQL-NMD) is a specific module of the PedsQL. Existing versions of this questionnaire include Acute version and Standard version, for Toddlers (2-4 years of age), Young Child (5-7 years of age), Child (812 years of age), Adolescent (13-18 years of age). The neuromuscular module was developed for neuromuscular disorders such as spinal muscular atrophy (SMA), DMD and other chronic conditions. Whilst this instrument may contain items that are relevant to those with DMD, it should be noted that the construct of the PedsQL-NMD was developed with participants aged from 18 to 80 years.

\section{Important aspects of QoL to DMD}

The literature suggests that many aspects of QoL are important to those with DMD, but the majority of these have been determined in a top-down fashion via existing instruments. It is possible that the incorporation of additional or alternative QoL themes into QoL assessment in DMD using a bottom-up approach with the choice of a wider choice of themes could benefit the study of QoL 
in this specific condition. Qualitative studies that build upon the themes identified in this review, undertaken with children and adolescents with DMD may identify new themes, or highlight QoL themes that are not relevant.

\section{The importance of age}

Age is an important factor to consider when measuring the impact of any condition upon QoL. The degree to which a child can self-complete a questionnaire is dependent upon their ability. Young children may require assistance with reading the questionnaire, and the administrative procedures. The task burden (which incorporates both the complexity of the questionnaire, and the number of items within it) will influence the quality of the data an instrument is able to provide. Instruments that contain a large number of items may mean that younger children are unable to reliably complete them. Matza et al. (2004) [48] identified a number of considerations to be made when designing a paediatric QoL instrument. The first is the age at which children can report their own health. Children appear able to reliably report on their own health between the ages of 4 and 6 years [49-53].

The issue of age within the context of DMD is of particular importance. With the recognised deterioration of individual's physical ability, it could be hypothesised that QoL would deteriorate with increasing age; however, this was not confirmed by the literature. There were inconsistent findings with regards to the patients deterioration in QoL over time with some reporting changes in at least one domain according to ambulatory status [54] and others suggesting that QoL remained stable despite declines in physical functioning [24, 44, 55]. However these inferences are often based on the comparison of DMD patients in cross-sectional or case-control study designs and therefore suitably powered follow-up studies using tools which are appropriate to capture meaningful changes to QoL with age are required. It is difficult to draw conclusions regarding the effect of age on DMD based upon evidence in the literature. Future efforts to study QoL in DMD or develop a DMD-specific QoL instrument should anticipate and accommodate the complexities of eliciting responses from young children, adolescents and young adults whose ability to communication will reduce over time.

\section{Culture and context}

Due to the inclusion of studies from around the world there were some geographical differences observed in the DMD research populations. Unsurprisingly the type and amount of formal care offered to patients and their families varies between countries [56]. One study documents that adults with DMD had higher HRQoL scores in Western Europe than those in countries in Eastern
European countries [28]. One study conducted in India found that the caregivers participating in the study were mostly male, owing perhaps in part, to cultural differences in research participation [33].

\section{Limitations of this review}

Limiting study eligibility to the last 5 years means that relevant studies published prior to 2010 may have been missed. However, as QoL themes that are known to be relevant are most likely to continue to receive attention it is less likely that important themes have not be captured by the data conducted in the last 5 years. Moreover, it could be argued that themes that have not been investigated in the last 5 years are less likely to be relevant to patients today. Similarly, the restriction to academic papers published in the English language could equally result in missed relevant themes and therefore a more inclusive approach to future comprehensive reviews is recommended. Moreover, it is also unlikely that the omission of studies will affect the output of this review as the focus is on thematic analysis. The aim is therefore to encompass the most relevant themes rather than including all published evidence. The consensus of themes discussed in the primary studies adds confidence to the probability that data saturation was reached in this review and the majority of relevant themes were captured.

\section{Recommendations for future research}

This research highlights that factors relevant to QoL in DMD span all domains of the included HRQoL instruments and beyond. Many of the nuances specific to DMD, such as the impact on the carer and wider family, are not currently captured by standard HRQoL instruments. The breadth and diversity of themes and emerging trends in this review highlight the need to consult with patients and their families about what aspects of QoL need to be covered by the QoL instruments used. For example, themes relating specifically to accessibility and adaptation to key stages in the condition, communication, access to appropriate healthcare services, family resources, carer burden, and impact on the wider family require consideration to obtain a more holistic picture of QoL.

Health professionals and clinicians who work in DMD may be aware of the complex picture of QoL for people living with DMD but must work with researchers to raise the issue of the difficulties in capturing QoL in DMD as in other diseases occurring in children which are severe and incurable, and therefore impacting substantially on patients and carer's QoL. Future research in this area should therefore build on the themes identified from this review and consult with people with DMD and their families. A qualitative research approach could focus on specific areas, from the variety of themes identified, that require attention and identify which should 
be given more weight to capture QoL in this population. This work either could inform the use of generic HRQoL instruments or could lead to the development of a specific HRQoL instrument for DMD. The aim would be to ensure that primary research conducted in the field of DMD would eventually use specific standardised, user-validated methods to study QoL.

The importance of perspective (patient versus carer) when collecting QoL data needs to be highlighted in future research. Owing to the specific nature of DMD where communication of patients' QoL is/becomes difficult, the value of using accessible instruments that reflect user needs should be considered. Moreover, the complexities at play when interpreting differences between self and/or parent proxy report should be given due consideration.

Evidence from the literature demonstrates that DMD impacts upon an individual's QoL, however the measurement of this has been using either existing generic instruments, condition-specific measures for given aspects of QoL (such as anxiety or depression), or using clinical indicators as a proxy. There is little robust evidence exploring the impact of DMD from the patient perspective using qualitative methods. Recent approaches to instrument development in other areas have utilised qualitative data techniques to ensure high face and content validity to the items contained within a questionnaire [57-59].

\section{Conclusions}

Many factors relevant to people living with DMD are inadequately assessed with generic preference-based QoL instruments. Synthesising evidence from primary studies that investigate issues relevant to the QoL of people with DMD and their caregivers has generated a rich and varied profile of themes that are relevant to QoL, many of which do not easily fall under the common domains of standard QoL tools. Themes relating to phases of decline during the disease, the importance of accessible services and family resources, and the impact on the family are key to the measurement of QoL in this unique condition. Those interested in obtaining more valid estimates of QoL in this specific population should use this information to inform further qualitative research and consider which aspects of QoL are appropriate to understand and measure in DMD.

\section{Additional file}

Additional file 1: Sample search for Embase (Ovid). (DOCX $14 \mathrm{~kb}$ )

\section{Abbreviations}

BMD: Becker Muscular Dystrophy; DMD: Duchenne Muscular Dystrophy; HRQoL: Health-Related Quality of Life; LGMD: Limb Girdle Muscular Dystrophy; QoL: Quality of Life
Acknowledgments

Not applicable.

Funding

This project was funded by Duchenne UK.

Availability of data and materials

Not applicable.

Authors' contributions

LU, JC and JB devised the study protocol. LU designed the methods, conducted the review and wrote the draft manuscript. HBW performed the literature searches. All authors have read and agreed the final version of the manuscript.

\section{Competing interest}

The authors declare that they have no competing interest.

Ethics approval and consent to participate

Not applicable.

Consent for publication

Not applicable.

\section{Publisher's Note}

Springer Nature remains neutral with regard to jurisdictional claims in published maps and institutional affiliations.

Received: 29 January 2018 Accepted: 9 December 2018

Published online: 19 December 2018

\section{References}

1. Mendell JR, et al. Evidence-based path to newborn screening for duchenne muscular dystrophy. Ann Neurol. 2012;71(3):304-13.

2. Bendixen RM, et al. Participation and quality of life in children with Duchenne muscular dystrophy using the international classification of functioning, disability, and health. Health Qual Life Outcome. 2012;10:43.

3. Bushby K, et al. Diagnosis and management of Duchenne muscular dystrophy, part 1: diagnosis, and pharmacological and psychosocial management. Lancet Neurol. 2010;9(1):77-93.

4. Witte RA. The psychosocial impact of a progressive physical handicap and terminal illness (Duchenne muscular dystrophy) on adolescents and their families. Br J Med Psychol. 1985;58(2):179-87.

5. Gagliardi BA. The impact of Duchenne muscular dystrophy on families. Orthop Nurs. 1991;10(5):41-9.

6. Grootenhuis MA, De Boone J, Van der Kooi AJ. Living with muscular dystrophy: health related quality of life consequences for children and adults. Health Qual Life Outcomes. 2007:5(1):1.

7. Baiardini I, et al. Quality of life in Duchenne muscular dystrophy: the subjective impact on children and parents. J Child Neurol. 2011;26(6):707-13.

8. Bray P, et al. Health related quality of life in boys with Duchenne muscular dystrophy: agreement between parents and their sons...Occupational therapy Australia, 24th National Conference and exhibition, 29 June - 1 July 2011. J Child Neurol. 2010:58:43.

9. Kohler M, et al. Quality of life, physical disability, and respiratory impairment in Duchenne muscular dystrophy. Am J Respir Crit Care Med. 2005;172(8):1032-6.

10. Longo-Araujo de Melo E, Moreno-Valdes MT. Evaluation of the quality of life of children with Duchenne's progressive muscular dystrophy. Rev Neurol. 2007;45(2):81-7.

11. Simon VA, et al. Evaluation of the quality of life in patients with Duchenne muscular dystrophy. Neuromuscul Disord. 2011;21(9-10):652.

12. Wei Y, et al. The relationship between quality of life and health-related quality of life in young males with Duchenne muscular dystrophy. Dev Med Child Neurol. 2017;59(11):1152-7.

13. McPhail S, Beller E, Haines T. Two perspectives of proxy reporting of healthrelated quality of life using the Euroqol-5D, an investigation of agreement. Med Care. 2008:46(11):1140-8.

14. Marques JC, et al. Comparison of child self-reports and parent proxy-reports on quality of life of children with attention deficit hyperactivity disorder. Health Qual Life Outcomes. 2013;11(1):186. 
15. Capitello TG, et al. What factors influence parents' perception of the quality of life of children and adolescents with neurocardiogenic syncope? Health Qual Life Outcomes. 2016;14(1):79.

16. Nolan, L. An exploration of proxy-and self-reported adolescent health in low-resource settings. In Survey Research Methods. 2016;10(2):65-83.

17. Ozyurt $G$, et al. Quality of life and sleep in children diagnosed with duchenne muscular dystrophy and their mothers' level of anxiety: a casecontrol study. Dusunen Adam. 2015;28(4):362-8.

18. Magliano $L$, et al. Psychological and practical difficulties among parents and healthy siblings of children with Duchenne vs. Becker muscular dystrophy: an Italian comparative study. Acta Myologica. 2014;33(3):136-43.

19. Wei S, Campbell C, Speechley K. Health-related quality of life in children with Duchenne muscular dystrophy. Can J Neurol Sci. 2014;41:S15.

20. Landfeldt E, et al. Quantifying the burden of caregiving in Duchenne muscular dystrophy. J Neurol. 2016;263(5):906-15.

21. Messina $\mathrm{S}$, et al. Health-related quality of life and functional changes in DMD: a 12-month longitudinal cohort study. Neuromuscul Disord. 2016; 26(3):189-96.

22. Hunt A, et al. Pain experience, expression and coping in boys and young men with Duchenne muscular dystrophy - a pilot study using mixed methods. Eur J Paediatr Neurol. 2016;20(4):630-8.

23. Wong $\mathrm{SH}$, et al. A mixed methods study of age at diagnosis and diagnostic odyssey for Duchenne muscular dystrophy. Eur J Hum Genet. 2015;23(10): 1294-300.

24. Elsenbruch S, et al. Self-reported quality of life and depressive symptoms in children, adolescents, and adults with Duchenne muscular dystrophy: a cross-sectional survey study. Neuropediatrics. 2013:44(5):257-64.

25. Ly H, Bertorini T. An Evaluation of Social and Medical Support for Adult Stage Duchenne Muscular Dystrophy (PD3. 003). Neurology. 2013;80(7 Supplement):PD3-003.

26. Madsen A, et al. Living conditions and quality of life in adults with Duchenne muscular dystrophy-a Danish survey. Neuromuscul Disord. 2014; 24(9-10):913.

27. Martinsen B, Dreyer P. Dependence on care experienced by people living with Duchenne muscular dystrophy and spinal cord injury. J Neurosci Nurs. 2012;44(2):82-90.

28. Steffensen $B$, et al. Health related quality of life in European adults with DMD: results from the care-NMD-project. Neuromuscul Disord. 2015;25: S302.

29. Reha A, et al. Disease-related symptoms and activities of daily living: a novel survey of patients with nonsense mutation Duchenne muscular dystrophy. J Neurol. 2014;261:S31-2.

30. Peay H. Prioritizing the worries of parents of children with Duchenne muscular dystrophy using best-worst scaling. Neuromuscul Disord. 2013; 23(9-10):755.

31. Heutinck $L$, et al. Physical activity in boys with DMD is lower and less demanding compared to healthy boys. Neuromuscul Disord. 2015;25: S303-4.

32. Davison $\mathrm{G}$, et al. A qualitative study exploring the impact on social wellbeing of young people living with a life-limiting neuromuscular disease. Dev Med Child Neurol. 2011;53:43.

33. Thomas PT, Rajaram P, Nalini A. Psychosocial challenges in family caregiving with children suffering from Duchenne muscular dystrophy. Health Soc Work. 2014;39(3):144-52.

34. Garralda ME, et al. Emotional impact of genetic trials in progressive paediatric disorders: a dose-ranging exon-skipping trial in Duchenne muscular dystrophy. Child Care Health Dev. 2013;39(3):449-55.

35. Klingels K, et al. Development of a patient-reported outcome measure for upper limb function in Duchenne muscular dystrophy: DMD upper limb PROM. Dev Med Child Neurol. 2016;26:26.

36. Pangalila RF, et al. Subjective caregiver burden of parents of adults with Duchenne muscular dystrophy. Disabil Rehabil. 2012;34(12):988-96.

37. Dany $\mathrm{A}$, et al. Construction of a quality of life questionnaire for slowly progressive neuromuscular disease. Qual Life Res. 2015;24(11):2615-23.

38. Pangalila R. Quality of life in Duchenne muscular dystrophy: the disability paradox. Dev Med Child Neurol. 2016:58(5):435-6.

39. Landfeldt $E$, et al. Health-related quality of life in patients with Duchenne muscular dystrophy: a multinational, cross-sectional study. Dev Med Child Neurol. 2016;58(5):508-15.

40. Brazier J, et al. Should patients have a greater role in valuing health states? Appl Health Econ Health Policy. 2005;4(4):201-8.
41. Wei $Y$, et al. Factors associated with health-related quality of life in children with Duchenne muscular dystrophy. J Child Neurol. 2016;31(7):879-86.

42. Houwen-van Opstal SL, et al. Health-related quality of life and its relation to disease severity in boys with Duchenne muscular dystrophy: satisfied boys, worrying parents--a case-control study. J Child Neurol. 2014;29(11):1486-95.

43. Pangalila RF, et al. Prevalence of fatigue, pain, and affective disorders in adults with duchenne muscular dystrophy and their associations with quality of life. Arch Phys Med Rehabil. 2015;96(7):1242-7.

44. Uzark K, et al. Health-related quality of life in children and adolescents with Duchenne muscular dystrophy. Pediatrics. 2012;130(6):e1559-66.

45. Magliano L, et al. Burden, professional support, and social network in families of children and young adults with muscular dystrophies. Muscle Nerve. 2015;52(1):13-21.

46. Soares De Moura $\mathrm{M}$, et al. Is functional dependence of Duchenne muscular dystrophy patients determinant of the quality of life and burden of their caregivers? Neuromuscul Disord. 2015;25:S202

47. Jardine J, et al. Self-reported quality of life of young children with conditions from early infancy: a systematic review. Pediatrics. 2014; 134(4):e1129-48.

48. Matza $L$, et al. Assessment of health-related quality of life in children: a review of conceptual, methodological, and regulatory issues. Value Health. 2004;7(1):79-92.

49. Juniper EF. Health-related quality of life in asthma. Curr Opin Pulm Med. 1999;5(2):105.

50. Annett RD. Assessment of health status and quality of life outcomes for children with asthma. J Allergy Clin Immunol. 2001;107(5):S473-81.

51. Connolly MA, Johnson JA. Measuring quality of life in paediatric patients. Pharmacoeconomics. 1999;16(6):605-25

52. Stevens KJ. Working with children to develop dimensions for a preferencebased, generic, pediatric, health-related quality-of-life measure. Qual Health Res. 2010;20(3):340-51.

53. Carlton J. Identifying potential themes for the child amblyopia treatment questionnaire. Optom Vis Sci. 2013;90(8):867-73.

54. Lue YJ, Chen SS, Lu YM. Quality of life of patients with Duchenne muscular dystrophy: from adolescence to young men. Disabil Rehabil. 2017;39(14):1408-13.

55. Geers, B., et al. Health-related quality of life in patients with Duchenne Muscular Dystrophy. Neuropediatrics. Conference: 37th Annual Meeting of the Society of Neuropediatrics. Garmisch Partenkirchen Germany. Conference Start, 2011. 42(no pagination).

56. Cavazza M, et al. Social/economic costs and health-related quality of life in patients with Duchenne muscular dystrophy in Europe. Eur J Health Econ 2016;17(Suppl 1):19-29.

57. Connell J, et al. Quality of life of people with mental health problems: a synthesis of qualitative research. Health Qual Life Outcomes. 2012;10(1):138.

58. Connell J, O'Cathain A, Brazier J. Measuring quality of life in mental health: Are we asking the right questions? Soc Sci Med. 2014;120:12-20.

59. Brazier, J., et al., A systematic review, psychometric analysis and qualitative assessment of generic preference-based measures of health in mental health populations and the estimation of mapping functions from widely used specific measures. 2014

60. McSweeney N, Lynch BJ. Correlation of quality of life with disease course and severity in an Irish Duchenne muscular dystrophy (DMD) population. Eur J Paediatr Neurol. 2011;15:S12.

61. Nozoe KT, et al. The relationship between sexual function and quality of sleep in caregiving mothers of sons with duchenne muscular dystrophy. Sex Med. 2014;2(3):133-40.

62. Bray $P$, et al. Health status of boys with Duchenne muscular dystrophy: a parent's perspective. J Paediatr Child Health. 2011;47(8):557-62

63. Peay HL, et al. Mothers' psychological adaptation to Duchenne/Becker muscular dystrophy. Eur J Hum Genet. 2016;24(5):633-7.

64. Bloetzer $C$, et al. Sleep disorders in boys with Duchenne muscular dystrophy. Acta Paediatr. 2012;101(12):1265-9.

65. McSweeney N, Lynch B. Correlation of quality of life with disease course and severity in an Irish duchenne muscular dystrophy(DMD) population. Ann Neurol. 2010:68:596.

66. Zamani $\mathrm{G}$, et al. The quality of life in boys with Duchenne muscular dystrophy. Neuromuscul Disord. 2016;26(7):423-7.

67. Mason S, et al. Exploring adherence to medical guidelines and quality of life for australians with duchenne muscular dystrophy. Twin Res Hum Genet. 2016;19(5):559. 
68. Riss VJ, Finanger EL, Russman BS. Fractures, functional status, and healthrelated quality of life in duchenne muscular dystrophy (DMD). Ann Neurol. 2012;72:S230.

69. Bendixen RM, et al. Participation in daily life activities and its relationship to strength and functional measures in boys with Duchenne muscular dystrophy. Disabil Rehabil. 2014;36(22):1918-23.

70. Lim Y, Velozo C, Bendixen RM. The level of agreement between child selfreports and parent proxy-reports of health-related quality of life in boys with Duchenne muscular dystrophy. Qual Life Res. 2014;23(7):1945-52.

Ready to submit your research? Choose BMC and benefit from:

- fast, convenient online submission

- thorough peer review by experienced researchers in your field

- rapid publication on acceptance

- support for research data, including large and complex data types

- gold Open Access which fosters wider collaboration and increased citations

- maximum visibility for your research: over $100 \mathrm{M}$ website views per year

At $\mathrm{BMC}$, research is always in progress.

Learn more biomedcentral.com/submissions 